\title{
PENGARUH VARIASI WAKTU AGING TERHADAP SIFAT MEKANIS PADUAN ALUMINIUM COR A356 SEBAGAI BAHAN PROPELER KAPAL
}

\author{
Suyanto*, Sri Pramono dan Riyanto Wibowo \\ Jurusan Teknik Bangunan Kapal, ATP Veteran Semarang \\ Jl. Pawiyatan Luhur IV No. 18 Bendan Dhuwur Semarang 50235. \\ "Email: suyantoeste@yahoo.com
}

\begin{abstract}
Salah satu cara untuk meningkatkan sifat mekanis bahan aluminium paduan adalah dengan perlakuan panas T6. Perlakuan panas yang dilakukan meliputi langkah: 1) solutioning yaitu menahan material pada suhu $540^{\circ} \mathrm{C}$ selama 1 jam, 2) quenching yaitu melakukan pendinginan cepat dengan mencelupkan material ke dalam air pada suhu kamar, dan 3) aging yaitu menahan material pada suhu aging $180^{\circ} \mathrm{C}$ selama 1, 2, 3, dan 4 jam. Hasil dari uji tarik dan kekerasan menunjukkan bahwa nilai kekuatan tarik dan kekerasan tertinggi dicapai pada waktu aging 3 jam, dengan nilai berturut-turut 181,8 MPa dan 97,7 HRB. Waktu aging melebihi 4 jam akan berpengaruh pada penurunan kekuatan tarik dan kekerasan material.
\end{abstract}

Kata kunci: aluminium, kekerasan, kekuatan, T6

\section{PENDAHULUAN}

Aluminium murni adalah jenis logam yang masih mempunyai sifat lunak jika dijadikan bahan suatu komponen. Untuk meningkatkan kekuatan aluminium biasanya dipakai dua cara yaitu memadu dengan unsur lain, dan cara perlakuan panas. Menurut Meier (2004), cara optimum untuk penguatan aluminium adalah memadunya dengan unsur lain, dan dengan perlakuan panas. Tujuannya adalah untuk membentuk butir yang halus dan pembentukan precipitat untuk menghambat gerakan dislokasi. Aluminium murni tidak bisa dikeraskan dengan perlakuan panas, karena tidak mempunyai unsur pemadu yang cukup untuk membentuk precipitat. Maka disaratkan adanya unsur pemadu semisal $\mathrm{Cu}, \mathrm{Zn}$, dan $\mathrm{Mg}$ dengan prosentase yang cukup sebagai pembentuk precipitat.

Salah satu jenis paduan aluminium yang sering digunakan pada industri kapal, khususnya untuk pembuatan propeler adalah aluminium jenis A356. Jenis paduan ini juga banyak digunakan pada industri otomotif. Hal tersebut dikarenakan paduan aluminium A356 mempunyai sifat mampu tuang yang baik, serta kekuatan yang tinggi. Penggunaan A356 sebagai bahan propeler kapal tradisional dengan proses pengecoran menghasilkan produk dengan sifat mekanis seperti kekuatan tarik dan kekerasan yang masih rendah. Suyanto dan Syafaat (2018) melakukan penelitian tentang sifat mekanis propeler cor yang dibuat dengan bahan A356. Hasil penelitian tersebut menunjukkan bahwa kekuatan tarik bahan propeler sebesar 139,2 MPa. Nilai tersebut lebih rendah jika dibandingkan dengan kekuatan tarik material A356 standar yaitu sebesar $172 \mathrm{MPa}-$ 234 MPa (ASM Handbook, 1992). Kekuatan tarik yang dimiliki bahan propeler lebih rendah $18 \%$ dibanding harga standarnya. Hasil pengujian juga menunjukkan sifat material propeler yang getas, dengan nilai regangan sebesar $2,48 \%$.

Salah satu cara untuk meningkatkan sifat mekanik bahan aluminium paduan adalah dengan perlakuan panas. T6 adalah salah satu perlakuan panas yang sering digunakan pada aluminium paduan. Proses T6 meliputi langkah solutioning yaitu menahan material pada kondisi temperatur sedikit di bawah temperatur eutectic, dengan tujuan melaurtkan precipitat yang ada sehingga terbentuk solid solution yang homogen dalam bentuk fase $\alpha$. Langkah berikutnya adalah quenching yaitu melakukan pendinginan cepat dengan mencelupkan material ke dalam cairan pendingin berupa minyak atau air. Langkah ini bertujuan membentuk super saturated solid solution. Langkah terakhir adalah aging yaitu menahan material pada suhu aging konstan dalam jangka waktu tertentu. Langkah ini bertujuan untuk mencapai terbentuknya precipitat baru dengan ukuran dan sebaran yang lebih homogen. Terbentuknya precipitat baru ini akan berpengaruh pada peningkatan sifat mekani bahan seperti kekuatan tarik dan kekerasan.

Penelitian tentang perlakuan panas pada aluminium paduan yang pernah dilakukan diantaranya oleh Zulfia dkk., (2010), yang meneliti tentang proses aging pada paduan aluminium AA333 hasil proses sand casting. Penelitian tersebut dilatarbelakangi oleh banyaknya pemakaian aluminium AA333 untuk 
bahanan industri otomotif. Namun AA333 pada kondisi as cast masih memiliki sifat mekanik yang rendah. Perlakuan panas yang dipilih adalah $\mathrm{T} 6$, diawali dengan solution treatmen pada suhu $525{ }^{\circ} \mathrm{C}$ selama 8 jam, kemudian dilanjutkan proses quenching. Proses aging dengan suhu $180{ }^{\circ} \mathrm{C}$ divariasikan waktunya 25 menit, $1,5,8$, dan 16 jam. Sedangkan untuk aging dengan waktu 5 jam divariasikan suhunya $110{ }^{\circ} \mathrm{C}, 150{ }^{\circ} \mathrm{C}, 180{ }^{\circ} \mathrm{C}$, $200{ }^{\circ} \mathrm{C}$, dan $250{ }^{\circ} \mathrm{C}$. Hasil penelitian menunjukkan bahwa kekuatan optimum dicapai pada suhu aging $180^{\circ} \mathrm{C}$ selama 5 dan 8 jam.

Kai $\mathrm{Wu}(2012)$, dalam tulisannya tentang prediksi respon aluminium cor terhadap perlakuan panas menyebutkan bahwa aluminium hasil pengecoran tidak dapat dikeraskan dengan proses work hardening, melainkan harus dikuatkan dengan precipitat fasa kedua dalam matrik paduan dengan cara heat treatmen. Secara umum heat treatmen terdiri dari solutionizing, quenching, dan aging. Material yang dipakai dalam penelitiannya adalah A356, dengan penambahan AlTiB 0,2\%. Solutionizing dilakukan pada suhu $546{ }^{\circ} \mathrm{C}$ selama 12 jam, kemudian quenching dilakukan dengan mencelupkan bahan dalam air bersuhu $80{ }^{\circ} \mathrm{C}$, dilanjutkan dengan aging pada suhu 155 ${ }^{\circ} \mathrm{C}$ selama 4 jam.

Pezda (2014), dalam jurnalnya menyebutkan bahwa perlakuan panas T6 dengan parameter tertentu biasa dilakukan untuk melakukan perubahan sifat mekanik material khususnya aluminium dan paduannya. Perlakuan panas T6 akan menghasilkan material yang mempunyai precipitat berupa partikel $\mathrm{Mg}_{2} \mathrm{Si}$ atau $\mathrm{Al}_{2} \mathrm{Cu}$ dalam butiran yang terbentuk selama proses aging. Aging adalah faktor yang sangat penting dalam heat treatmen, karena temperatur dan waktu yang dipilih akan sangat menentukan perubahan kekuatan tarik dan elongation material. Pilihan temperatur aging rendah (misalkan $165{ }^{\circ} \mathrm{C}$ ) akan memberikan efek yang signifikan pada kekuatan tarik, namun cenderung menurunkan elongation material. Sedangkan aging dengan pilihan suhu tinggi (misalkan $325{ }^{\circ} \mathrm{C}$ ) atau diatasnya berpengaruh pada peningkatan elongation material, namun menurunkan kekuatan tarik.

Pertimbangan temperatur aging tersebut menjadi dasar bagi Pezda (2014), untuk melakukan penelitian tentang pengaruh perlakuan panas terhadap sifat mekanik paduan $\mathrm{Al}-\mathrm{Si}-\mathrm{Mg}$ hipoeutektoid yaitu aluminium paduan A356. Material tersebut dipilih dengan pertimbangan banyak dipakai pada bidang otomotif khusunya untuk bahan veleg, cilinder blok, dan pompa part pada pesawat. Kelebihan AA356 yang lain adalah memiliki kekuatan tinggi dengan bobot yang ringan, mempunyai mampu tuang yang baik, tahan korosi, dan harganya murah. Perlakuan panas yang dipilih adalah T6 dengan temperatur solid solubility 465-550 ${ }^{\circ} \mathrm{C}$ selama $0,5-3$ jam, dilanjutkan dengan aging pada temperatur $165^{\circ} \mathrm{C}-325^{\circ} \mathrm{C}$ selama 2-8 jam. Dari penelitian ini disimpulkan bahwa kekuatan tarik tertinggi dicapai pada proses solid solubility $520-530{ }^{\circ} \mathrm{C}$ dengan waktu $0,5-3$ jam, dilanjutkan dengan aging pada temperatur $165^{\circ} \mathrm{C}$ selama 5-8 jam.

Penelitian laku panas T6 terhadap paduan Aluminium dilakukan dengan tahapan solutioning, quenching, dan aging. Dari ketiga tahapan tersebut, beberapa peneliti mengambil variabel suhu solutioning dan aging yang hampir sama. Namun variabel waktu solutioning dan aging yang diambil oleh beberapa peneliti sangat bervariasi. Moller dkk., (2008), Abdulwahab dkk., (2012), Yulfitra dan Iswanto (2012), menggunakan suhu solutioning $540{ }^{\circ} \mathrm{C}$. Sementara itu Anzip dan Suhariyanto (2006), Abdillah (2012), dan Ridvan dkk., (2018), menggunakan suhu solutioning berturut-turut $538{ }^{\circ} \mathrm{C}, 535{ }^{\circ} \mathrm{C}$, dan $520{ }^{\circ} \mathrm{C}$. Terkait dengan waktu penahanan pada proses solutioning, Yulfitra dan Iswanto (2012), menggunakan waktu 30 dan 60 menit, Abdulwahab dkk., (2012) menggunakan waktu 1 jam, Moller dkk., (2008) menggunakan waktu 1 jam dan 6 jam, Ridvan dkk., (2018), menggunakan waktu 4 jam, dan Anzip dan Suhariyanto (2006) menggunakan waktu 6 jam. Variasi suhu proses aging pada beberapa penelitian bervariasi, dan rata-rata mengambil suhu aging $150{ }^{\circ} \mathrm{C}$ hingga $200{ }^{\circ} \mathrm{C}$. Waktu penahanan aging bervariasi antara 1 hingga 7 jam.

Perlakuan panas yang dikenakan pada aluminium paduan bertujuan untuk meningkatkan sifat mekanis, terutama kekerasan kan kekuatan tarik material. Dari beberapa penelitian yang di lakukan, kekerasan dan kekuatan tertinggi dicapai setelah proses aging yang bervariasi. Penelitian Ridvan dkk., (2018) mencapai nilai kekuatan dan kekerasan tertinggi dengan suhu aging $180{ }^{\circ} \mathrm{C}$ dalam waktu 20 menit. Moller dkk., (2008) mencapai kekuatan dan kekerasan tertinggi dengan suhu aging $180{ }^{\circ} \mathrm{C}$ selama 1 jam. Yulfitra dan 
Iswanto (2012), mencapai kekuatan dan kekerasan tertinggi dengan suhu aging $200{ }^{\circ} \mathrm{C}$ selama 2 jam. Abdulwahab dkk., (2012) mencapai kekuatan dan kekerasan tertinggi dengan suhu aging $200{ }^{\circ} \mathrm{C}$ selama 3 jam. Setelah mencapai nilai kekerasan dan kekuatan optimum, jika waktu penahanan pada proses aging ditambah, maka kekuatan tarik dan kekerasan akan cenderung menurun. Hal itu terjadi karena penambahan waktu aging akan memberikan kesempatan terjadinya pertumbuhan butir. Dan ini akan berpengaruh pada penurunan kekerasan dan kekuatan (Ridvan dkk., 2018).

\section{METODOLOGI}

\section{Pengecoran Propeler}

Pengecoran propeler aluminium dilakukan di UMKM industri pengecoran logam Juwana Pati. Pengecoran menggunakan bahan aluminium ingot yang siap pakai. Setelah produk propeler jadi, kemudian di buat spesimen uji tarik, uji kekerasan, dan uji komposisi dengan memotong daun propeler.

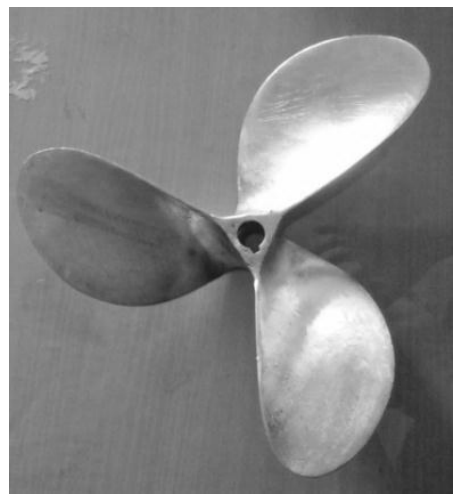

\section{Gambar 1. Propeler aluminium as cast}

\section{Perlakuan Panas}

Perlakuan panas yang dikenakan pada bahan propeler aluminium adalah T6. Proses T6 di lakukan di Laboratorium Material Teknik Universitas Wahid Hasyim (Unwahas), dengan tahapan sebagai berikut:

1) Solutioning, yaitu menahan material pada suhu sedikit di bawah suhu eutectic yaitu 540C selama 1 jam, dengan tujuan melarutkan precipitat yang ada sehingga terbentuk solid solution yang homogen dalam bentuk fase $\alpha$.

2) Quenching, yaitu melakukan pendinginan cepat dengan mencelupkan material ke dalam air pada suhu kamar. Langkah ini bertujuan membentuk super saturated solid solution.

3) Aging, yaitu menahan material pada suhu aging 180C selama 1 jam, 2 jam, 3 jam, dan 4 jam. Langkah ini bertujuan untuk mencapai terbentuknya precipitat baru dengan ukuran dan sebaran yang lebih homogen.

\section{Uji Komposisi}

Uji Komposisi dilakukan guna mendapatkan nilai komposisi kimia dari unsurunsur yang terkandung dalam material aluminium paduan bahan propeler. Pengujian dilakukan dengan menggunakan spectrometer bertempat di Laboratorium Metalurgi Politeknik Manufaktur Ceper, Klaten. Spesimen uji komposisi disiapkan dengan potongan material dengan ketebalan $2 \mathrm{~cm}$. Spesimen uji komposisi di buat dengan ketebalan cukup agar tidak terjadi efek terbakar pada saat pengujian.

\section{Uji Tarik}

Uji tarik yang dilakukan bertujuan untuk mengetahui sifat mekanis material seperti kekuatan tarik, keuletan, kekakuan, serta ketangguhan material. Pelaksanaan uji tarik berdasarkan standar ASTM E-8M. Ukuran utama spesimen uji tarik adalah panjang ukur $25 \mathrm{~mm}$, lebar $6 \mathrm{~mm}$ dan tebal $3 \mathrm{~mm}$.

\section{Uji Kekerasan}

Uji kekerasan dilakukan dengan menggunakan alat uji Brinell berdasarkan standar ASTM E-10. Daun propeler dipotong kemudian dilakukan mounting untuk mempermudah pengaturan posisi spesimen ketika pengujian. Pengamplasan dilakukan untuk mendapatkan permukaan yang rata dan halus. Identor dikenakan pada permukaan penampang potongan dengan arah melintang dari daun propeler. Pengujian dilakukan di Laboratorium Material Teknik Unwahas.

\section{HASIL DAN PEMBAHASAN Uji Komposisi}

Hasil uji komposisi menunjukkan unsurunsur yang terkandung dalam bahan aluminium paduan seperti pada Tabel 1 .

Tabel 1. Komposisi bahan propeler

\begin{tabular}{cccccc} 
Unsur & Si & Fe & Cu & Mg & Zn \\
\hline $\begin{array}{c}\text { A356 } \\
\text { as cast }\end{array}$ & 7,48 & 0,78 & 0,12 & 0,42 & 0,46 \\
$\begin{array}{c}\text { A356 } \\
\text { Standar } \\
\text { ASM }\end{array}$ & $6,5-7,5$ & 0,6 & - & $\begin{array}{c}0,25- \\
0,45\end{array}$ & 0,35 \\
\end{tabular}


Tabel 1 menunjukkan bahwa unsur paduan dominan yang terdapat pada bahan propeler adalah $\mathrm{Si}$ sebesar 7,48\%, disusul $\mathrm{Fe}$ 0,78\%, dan Zn 0,46\%. Jika kita bandingkan dengan komposisi Aluminium paduan A356 standar ASM yang mempunyai unsur paduan $\mathrm{Si}$ $6,5 \%-7,5 \%$, Fe 0,6\%, Mg 0,25\%-0,45\%, dan Zn $0,35 \%$, maka didapatkan perbedaan antara dua aluminium paduan di tersebut, yaitu pada unsur Fe dan Zn. Material A356 standar hanya mengandung Fe dan $\mathrm{Zn}$ sekiar 0,6\% dan 0,35\%, sedangkan hasil uji komposisi material propeler menunjukkan kandung $\mathrm{Fe}$ dan $\mathrm{Zn}$ sebesar $0,78 \%$ dan $0,4 \%$. Unsur $\mathrm{Cu}$ pada material propeler terkandung sebesar $0,12 \%$. Kehadiran $\mathrm{Fe}, \mathrm{Cu}$, dengan prosentase cukup besar ini tentunya akan berpengaruh pada sifat mekanis material.

\subsection{Uji Tarik}

Uji tarik dilakukan berdasarkan standar ASTM E-8M. Hasil uji tarik menunjukkan nilai kekuatan tarik dan keuletan ditunjukkan pada Tabel 2

Tabel 2. Nilai kekuatan tarik dan keuletan

\begin{tabular}{ccc}
\hline $\begin{array}{c}\text { WAKTU } \\
\text { AGING } \\
(\mathrm{Jam})\end{array}$ & $\begin{array}{c}\text { KEKUATAN } \\
\text { TARIK } \\
(\mathrm{MPa})\end{array}$ & $\begin{array}{c}\text { KEULETAN } \\
(\%)\end{array}$ \\
\hline 0 & 165,2 & 10,2 \\
1 & 171,9 & 10,2 \\
2 & 176,6 & 8,3 \\
3 & 181,8 & 8,2 \\
4 & 169,4 & 9,0 \\
\hline
\end{tabular}

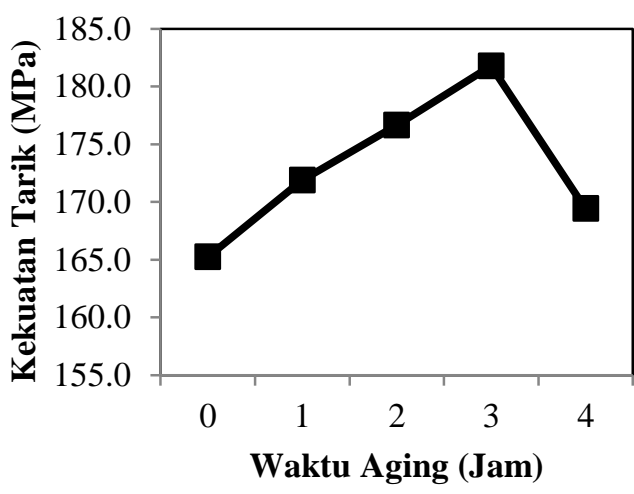

\section{Gambar 2. Nilai Kekuatan tarik material sebagai fungsi dari waktu aging}

Kekuatan tarik bahan propeler sebelum laku panas adalah 139,2 MPa. Setelah dilakukan solutioning dan quenching namun belum mengalami aging, kekuatan tariknya menjadi 165,2 MPa. Setelah dilakukan aging, kekuatan tarik terus meningkat hingga mencapai $181,8 \mathrm{MPa}$ pada waktu aging 3 jam. Namun ketika aging diteruskan melebihi 3 jam, kekuatan tariknya mulai menurun.

Faktor yang mempengaruhi terjadinya peningkatan nilai kekuatan tarik dan kekerasan bahan adalah terbentuknya precipitat $\mathrm{Mg}_{2} \mathrm{Si}$ di dalam matrik Al a (Ridvan dkk., 2018). Keberadaan precipitat ini terdispersi secara merata di batas butir dan berfungsi sebagai penghalang dan mempersulit terjadinya dislokasi, sehingga gaya yang diperlukan untuk mendeformasi semakin besar. Akibatnya adalah nilai kekerasan dan kekuatan material akan meningkat, namun keuletan material akan turun.

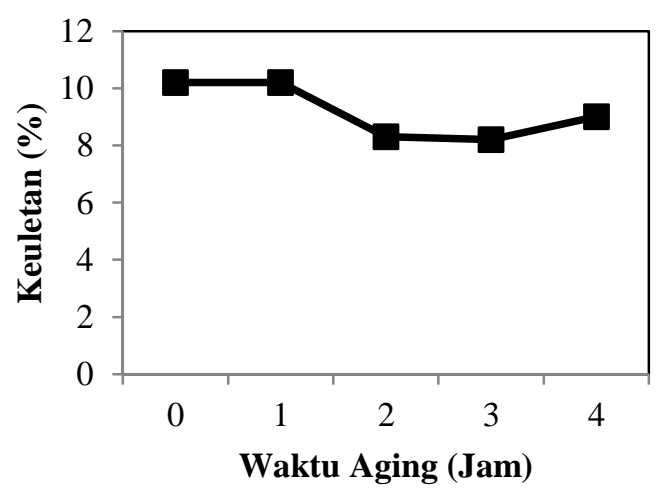

\section{Gambar 3. Nilai keuletan material sebagai fungsi dari waktu aging}

Keuletan bahan propeler sebelum laku panas adalah $5,2 \%$. Setelah mengalami solutioning dan quenching, dan belum mengalami aging keuletannya menjadi 10,2\%. Keuletan bahan makin menurun seiring dengan penambahan waktu aging, dan keuletan terendah adalah $8,2 \%$ terjadi saat waktu aging 3 jam. Kemudian keuletan kembali meningkat ketika waktu aging melebihi 3 jam.

\section{Uji Kekerasan}

Uji kekerasan material dilakukan berdasarkan standar ASTM E-10 dengan uji kekerasan Brinell. Hasil uji kekerasan material setelah medapatkan lakuan panas T6 dengan suhu aging $180{ }^{\circ} \mathrm{C}$ dan waktu aging yang divariasikan bisa dilihat pada Tabel 3 dan Gambar 4.

Tabel 3. Nilai uji kekerasan 


\begin{tabular}{cc}
\hline $\begin{array}{c}\text { WAKTU AGING } \\
\text { (Jam) }\end{array}$ & $\begin{array}{c}\text { KEKERASAN } \\
\text { (BHN) }\end{array}$ \\
\hline 0 & 91,0 \\
1 & 96,3 \\
2 & 97,3 \\
3 & 97,7 \\
\hline
\end{tabular}

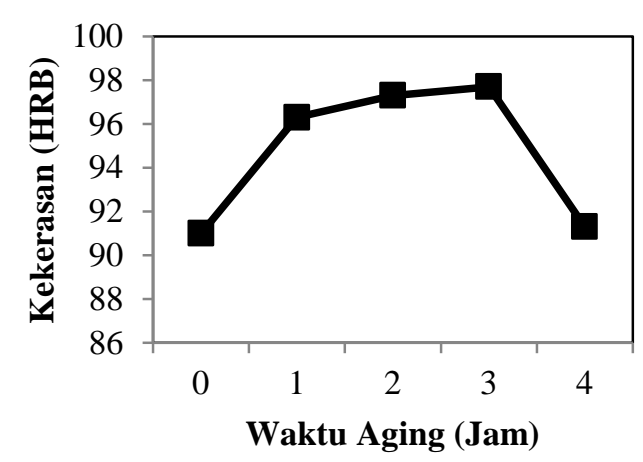

\section{Gambar 4. Nilai kekerasan material sebagai fungsi dari waktu aging}

Hasil uji kekerasan pada material propeler as cast menunjukkan nilai 83,6 BHN. Setelah mengalami solutioning dan quenching, dan belum mengalami aging, kekerasannya menjadi 91 BHN. Kekerasan terus meningkat seiring dengan penambahan waktu aging. Proses T6 mendapatkan hasil kekerasan tertinggi 97,7 BHN dicapai pada waktu aging 3 jam. Kekerasan kemudian menurun seiring penambahan waktu aging di atas 3 jam.

Nilai kekuatan tarik dan kekerasan bahan setelah mengalami laku panas T6 dengan waktu aging lebih dari 4 jam menyebabkan nilai kekerasan menurun. T6 dengan waktu yang terlalu lama akan memberikan kesempatan terjadinya pertumbuhan butir (Ridvan dkk., 2018). Dengan ukuran butir yang lebih besar ini akan berpengaruh terhadap penurunan nilai kekerasan dan kekuatan material, namun keuletan akan meningkat.

\section{KESIMPULAN}

1) Nilai kekuatan tarik dan kekerasan tertinggi dicapai pada waktu aging 3 jam, dengan nilai berturut-turut 181,8 MPa dan 97,7 HRB.

2) Nilai keuletan material akan turun ketika nilai kekuatan tarik dan kekerasa naik, demikian pula sebaliknya.

3) Waktu aging melebihi 4 jam akan berpengaruh pada penurunan kekuatan tarik dan kekerasan material.

\section{DAFTAR PUSTAKA}

Abdillah, F., (2012), Pengaruh Waktu Penahanan Artificial Aging Terhadap Sifat Mekanis dan Struktur Mikro Coran Paduan Al-7\%Si, Gardan, vol. 1, no.1, pp. 112-119.

Abdulwahab, M., Madugu, IA., Yaro, SA., Popoola, API., (2012), Effects of Temper Conditions and Step-Quenching-Ageing on the Hardness Characteristics and Yield Strength of A356.0-type Al-Si-Mg Alloy, Silicon, vol. 4, pp.137-143.

Anonimous, Properties and Selection Nonferrous Alloy and Special-Purpose Materials, ASM International, Vol. 2, (1992).

Anzip, A., Suhariyanto, (2006), Peningkatan Sifat Mekanik Paduan Aluminium A356.2 dengan Penambahan Manganese (Mn) dan Perlakuan Panas T6, Jurnal Teknik Mesin, vol. 8, No. 2, pp. $64-68$.

ASM Handbook, (1992)

Kai Wu, C., (2012), Predicting The Response of Aluminum Casting Alloys to Heat Treatment, Tesis, Worcester Polytechnic Institute.

Meier, M., (2004), Heat Treatment of Aluminium Alloys, Department of Chemical Engineering and Materials Science. University of California, Davis.

Moller, H., Govender, G., Stumpf, WE., (2008), Investigation of the T4 and T6 Heat Treatment Cycles of Semi-Solid Processed Aluminium Alloy A356, The Open Materials Science Journal, vol. 2, pp.11-18.

Pezda, J., (2014), The Effect of The T6 Heat Treatmen on Hardness and Microstructure of The En ACAlSi12CuNiMg Alloy, Metalurgija, vol. 53, no. 1, pp. 63-66.

Ridvan G., Serhat A., Alptekin K., Kerem AG., Ahmet K., (2018), Influence of T6 heat treatment on A356 and A380 aluminium alloys manufactured by thixoforging combined with low superheat casting, Trans. Nonferrous Met. Soc. China, vol. 28, pp. 385-392.

Suyanto, Syafaat, I., (2018), Analisis Sifat Mekanis Propeler Perahu Nelayan Tradisional Berbahan Aluminium, Momentum, vol 14, no. 1, pp. 33-38.

Yulfitra, Iswanto, PT., (2012), Pengaruh Variasi Waktu Solution Heat Treatmen dan Suhu Aging Perlakuan Panas T6 pada 
Centrifugal casting $400 \mathrm{rpm}$ dengan Grain Refiner AlTiB 7,5\% Terhadap Sifat Fisis dan Mekanis Paduan Aluminium Cor Velg Sepeda Motor, Simposium Nasional RAPI XI FT UMS 2012, Pp M48-M52.

Zulfia, A., Juwita, R., Uliana, A., Jujur, IN., Raharjo, J., (2010), Proses Penuaan (Aging) pada Paduan Aluminium AA 333 Hasil Proses Sand Casting, Jurnal Teknik Mesin, vol. 12, no. 1, pp. 13-20. 